\title{
EDUCATIONAL SATISFACTION OF SENIOR DENTAL STUDENTS TOWARDS PAEDIATRIC DENTISTRY AT KING SAUD UNIVERSITY, SAUDI ARABIA
}

\author{
Majedah A. Al-Homaidhi*
}

\begin{abstract}
Aim: We aimed to evaluate the attitude of senior dental students towards clinical education in paediatric dentistry.

Methods: This was a cross-sectional, descriptive study performed on dental students during their final (senior) year at King Saud University, Saudi Arabia. A structured questionnaire was used to collect data in two parts, i.e., demographic information of the participants (age and gender) and sixteen questions about the students' educational satisfaction towards the clinical education of pediatric dentistry. Data were analysed using the chi-square test with p-values $<0.05$ determining statistical significance.
\end{abstract}

Results: A total of 109 dental students were enrolled (56\% were male and $44 \%$ were female). There was a significant difference in the clinical education satisfaction level between male and female. Majority of the student had a sufficient knowledge about clinical procedures. However, only $41 \%$ and $45.9 \%$ students had a positive attitude towards education on drug prescription and pulp therapy of young permanent teeth, respectively.

Conclusion: The results of this study showed that senior dental students were satisfied with most of their clinical education received in paediatric courses, but there was a lack of knowledge on drug prescription and pulp therapy in young permanent teeth.

KEYWORDS: educational satisfaction, dental students, paediatric dentistry, clinical education.

\section{INTRODUCTION}

Dental caries continues to be one of the most common childhood diseases worldwide ${ }^{(1)}$.
Several studies have been conducted to evaluate the prevalence of dental caries worldwide, and these studies have revealed a higher prevalence among children from developing countries such

* Lecturer, College of Dentistry, King Saud University, Riyadh, Saudi Arabia. 
as China $(85 \%)^{(2)}$, India (48\%) ${ }^{(3)}$, and Sri Lanka $(68.8 \%)^{(4)}$ compared to children from developed countries such as England (32\%) ${ }^{(5)}$ and Switzerland (24.8\%). ${ }^{(6)}$ In a recent study conducted in Riyadh, Saudi Arabia by Al-meedani and Al-Dlaigan, about $69 \%$ of pre-school children had dental caries ${ }^{(7)}$. Therefore, dental caries remains a significant problem in Saudi Arabia with an increased demand for treatment.

When questions arise about the delivery of service, questions on the training of healthcare providers follow soon after. Subsequently, training competent, committed, and passionate dentists who are willing to serve the community is one of the educational priorities in the schools of dental sciences.

Effectiveness in teaching can be defined as the extent to which the teaching activity fulfils its intended purpose, function, and goal ${ }^{(8)}$. Dentistry is a discipline that includes several branches for specialization such as operative dentistry, oral and maxillofacial surgery, endodontics, paediatric dentistry, orthodontics, periodontics, prosthodontics, oral radiology, and oral pathology.

Paediatric dentistry is an age-defined specialty that provides both primary and comprehensive preventive and therapeutic oral health care for infants and children through adolescence, including those with special health care needs ${ }^{(9)}$. It is a specialty in which students learn to adapt techniques and procedures from general dentistry and specialties, in order to provide primary and comprehensive preventive and therapeutic oral health care to children of all ages. It relies on preventive dentistry, pulp therapy for primary and young permanent teeth, restoration of teeth, oral surgery for children, preventive and interceptive orthodontics, as well as controlling children's behaviours ${ }^{(10)}$.
Training and educating appropriate students in the clinical field is an important issue in education ${ }^{(11)}$. The education quality can best be assessed by the students themselves since they are the target group for educational programs ${ }^{(12)}$. A study conducted in a Jamaican dental school to evaluate the graduates' opinion on their abilities and its relationship with the curriculum found that the students perceived themselves to be well prepared for most aspects of dental practice, but highlighted areas requiring further curricular development such as conducting clinical research. The results of this study showed that the course curriculum should change to help strengthen the knowledge and clinical skills of dentistry students ${ }^{(13)}$.

Sajadi et al. also evaluated the attitude of Kerman dentistry students towards the curriculum in paediatric dentistry. Their results showed that students had a positive attitude towards clinical education in preventive dentistry and pulp therapy in children. However, there was a lack of proficiency among dentistry graduates in preventive orthodontic treatment and management of permanent traumatized teeth ${ }^{(14)}$.

Evaluation of the curriculums is one of the main responsibilities of any educational institute. In the College of Dentistry, King Saud University (KSU), undergraduate students must pass three courses to be able to treat children by themselves - the first one being laboratory and didactic, followed by one year of a clinical and didactic course and finally, one year of a clinical course. The graduates must be able to diagnose and treat children's oral problems as well as manage their behaviour. Therefore, appropriate training in these dental skills is of great importance. The aim of this study was to evaluate the educational satisfaction of senior dental students towards paediatric dentistry. 


\section{MATERIALS AND METHODS}

This cross-sectional survey study was approved by the College of Dentistry Research Centre, KSU, Riyadh, Saudi Arabia (CDRC; registration number FR0353). The study sample consisted of senior-year dental students enrolled in the College of Dentistry at KSU, Saudi Arabia, for the 2016/2017 academic year. The purpose of the study was explained in a cover page attached to the questionnaire and informed consent was obtained from all student participants.

The questionnaire, which was adapted from a previously used version with minor modifications ${ }^{(14)}$, consisted of two parts. The first part included demographic information of the student (age and gender) and the second part consisted of 16 questions on the students' satisfaction and knowledge of education in paediatric dentistry based on information received in paediatric courses. The questionnaire was scored on a Likert scale as follows: 5 = strongly agree, $4=$ agree, $3=$ neutral, $2=$ disagree, and $1=$ strongly disagree. Students were instructed to rate their knowledge in each topic using this 5-point scale.

A pilot study was conducted on 15 students of the study population who were excluded in the final analysis to test the validity and reliability of this questionnaire. Next, the questionnaires were distributed to study participants during a regular scheduled classroom lecture and they were instructed to fill out the questionnaire voluntarily and anonymously.
The collected data were analysed using SPSS ver. 17.0 (SPSS Inc., Chicago, IL, USA). The chisquare test was used to evaluate specific differences in characteristics by gender. Statistical significance was determined by P-values $<0.05$.

\section{RESULTS}

A total of 112 individuals initially completed the questionnaire, but after preliminary analyses, three questionnaires were excluded owing to missing data. The remaining 109 questionnaires were coded and entered into SPSS to perform data analyses. The mean age of subjects was 23.2 years (standard deviation $=0.798)$; of these, $61(56 \%)$ were males and $48(44 \%)$ were females. In this study, the mean score was $67.62 \pm 9.46$ for male and $62.71 \pm 7.83$ for female, showing a significant difference $(\mathrm{p}=0.005)$ (Table 1).

$74.1 \%$ of the students stated that they were well educated on sealant therapy, and $63.3 \%$ felt well educated in extraction of primary teeth. However, only $20.2 \%$ of the participants stated that they were well educated in the various pulp treatments of young permanent teeth. Moreover, $12.8 \%$ and $12.1 \%$ of the students were not satisfied with their education on the treatments of traumatic primary and permanent teeth, respectively (Table 2). There was a significant difference between the male and female participant in treatment planning, preventive resin restoration, stainless steel crowns and space maintainer application methods, restorations of deciduous and permanent teeth, as well as extraction of deciduous teeth (Fig 1). 
TABLE (1) The relationship between demographic variables and the scores obtained from questionnaires

\begin{tabular}{|c|c|c|c|c|c|}
\hline \multirow{2}{*}{ Sex } & N(\%) & Mean & Std. Deviation & p-value \\
\hline \multirow{3}{*}{ score } & Male & $61(56)$ & 67.62 & 9.46 & \multirow{2}{*}{0.005} \\
\cline { 2 - 5 } & Female & $48(44)$ & 62.71 & 7.83 & \\
\hline
\end{tabular}

TABLE (2) The frequency distribution of responses to the questionnaire

\begin{tabular}{|c|c|c|c|c|c|}
\hline Procedures & $\begin{array}{l}\text { Strongly } \\
\text { agree }\end{array}$ & agree & Neutral & disagree & $\begin{array}{l}\text { Strongly } \\
\text { disagree }\end{array}$ \\
\hline & $\%$ & $\%$ & $\%$ & $\%$ & $\%$ \\
\hline Treatment Planning & 52.3 & 43.1 & 4.6 & 0 & 0 \\
\hline Caries Risk Assessment & 43.1 & 41.3 & 11.9 & 3.7 & 0 \\
\hline Diet Analysis & 15.7 & 24.1 & 38.9 & 18.5 & 2.8 \\
\hline Drug Prescription & 14.7 & 26.6 & 45.9 & 11.9 & .9 \\
\hline Prophylaxis \& Fluoride Therapy & 56.9 & 28.4 & 11.9 & 1.8 & $0 \%$ \\
\hline Child Behaviour Management Technique & 18.3 & 36.7 & 36.7 & 6.4 & 1.8 \\
\hline Sealant Therapy & 74.1 & 19.4 & 4.6 & 1.9 & 0 \\
\hline Preventive Resin Restoration & 69.7 & 24.8 & 3.7 & 1.8 & 0 \\
\hline Treatment of Traumatic Deciduous Teeth & 20.2 & 36.7 & 26.6 & 12.8 & 3.7 \\
\hline $\begin{array}{c}\text { Treatment of Traumatic Young } \\
\text { Permanent Teeth }\end{array}$ & 22.4 & 32.7 & 29.0 & 12.1 & 3.7 \\
\hline Pulp Therapy of Deciduous Teeth & 39.4 & 44.0 & 15.6 & 9 & 0 \\
\hline Pulp Therapy of Young Permanent Teeth & 14.7 & 31.2 & 28.4 & 20.2 & 5.5 \\
\hline $\begin{array}{c}\text { Stainless Steel Crowns - Application } \\
\text { Method }\end{array}$ & 44.0 & 45.9 & 9.2 & .9 & 0 \\
\hline Space Maintainer - Application Method & 41.3 & 47.7 & 7.3 & 3.7 & 0 \\
\hline $\begin{array}{c}\text { Restoration of Deciduous \& Permanent } \\
\text { Teeth }\end{array}$ & 60.6 & 35.8 & 3.7 & 0 & 0 \\
\hline Extraction of Deciduous teeth & 63.3 & 30.3 & 6.4 & 0 & 0 \\
\hline
\end{tabular}




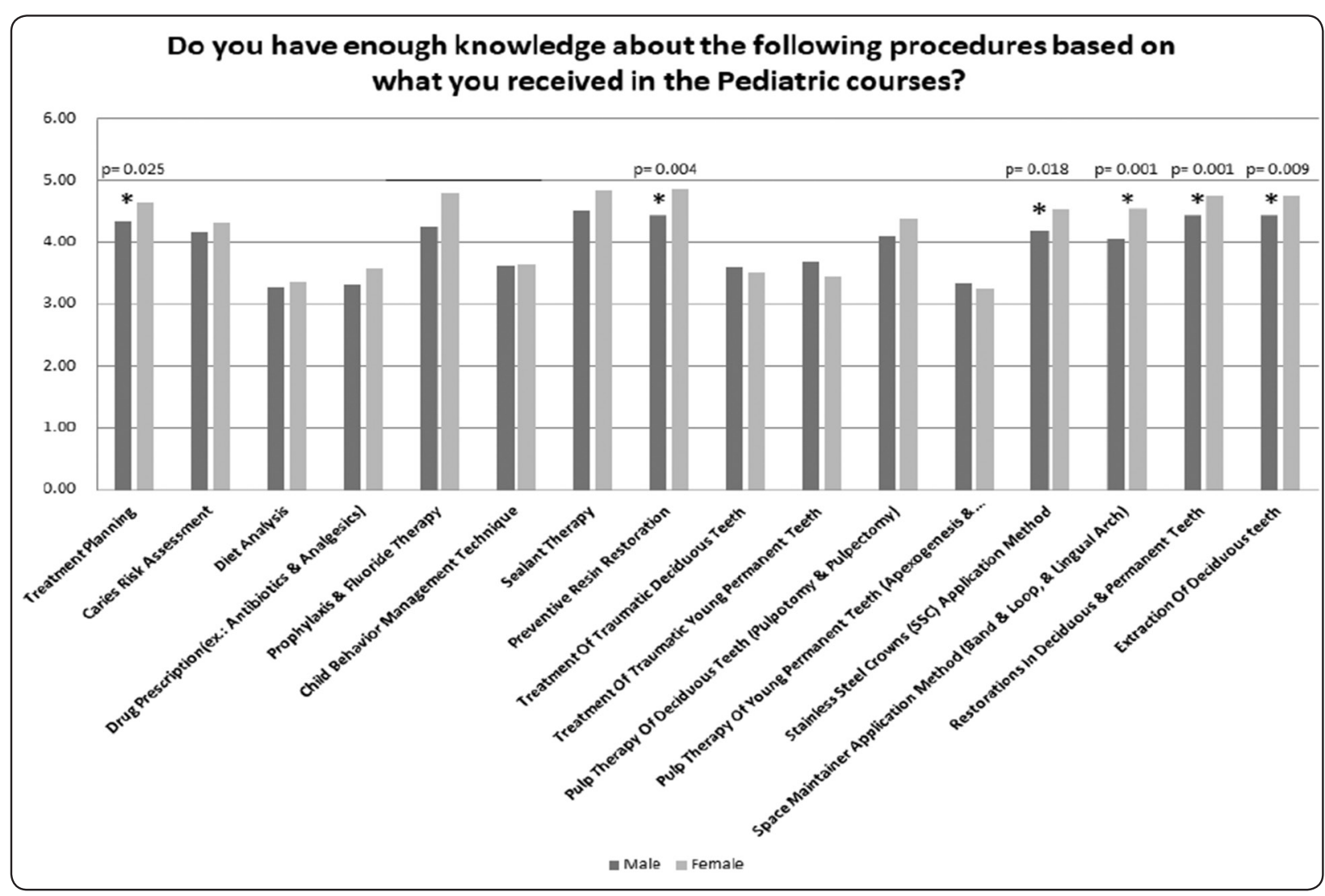

Fig. (1) Comparison of the scores of knowledge and attitude towards each procedure between male and female participants of the study

\section{DISCUSSION}

A routine curriculum evaluation by the students themselves is important to provide feedback and suggestions for the revision of curriculum and to improve the learning environment, because the students are the target centre of educational processes ${ }^{(8,15,16)}$. This study was conducted to assess the attitude of KSU senior year dental students towards clinical paediatric dentistry trainings.

Proper treatment planning for paediatric dental patients is a multi-factorial, complex process that requires careful consideration of distinct areas: the patient's caries risk status, the available treatment options, the patient's diet, and their behaviour ${ }^{(17)}$. In this study, the female participant students had better knowledge in creating a treatment plan than male.
Caries risk data in dentistry is still not sufficient to quantify the models, and this process should be a component in the clinical decision-making process ${ }^{(18)}$. The goal of training a student to accurately use the caries risk assessment tool has been achieved by the paediatric courses in KSU, as $84.4 \%$ of the students were satisfied with their knowledge on this procedure.

For the educational satisfaction of students towards preventive dentistry in children, $85 \%$ of the participants in this study agreed with fluoride therapy, $93.5 \%$ with sealant therapy, and $94.5 \%$ participants with preventive resin restoration. A study conducted in Saudi Arabia showed that the majority of dentists have sufficient awareness and motivation for preventive dental care, which is compatible with the results of the current study ${ }^{(19)}$. 
In a study conducted by the European association on paediatric courses in different dental schools showed that the graduates must learn behaviour management techniques in children ${ }^{(20)}$. In this study, $55 \%$ of the participants selected agree and strongly agree and $36.7 \%$ selected neutral as the response for the question on knowledge of children's behaviour management techniques, which suggests that the paediatric dentistry department in KSU, college of dentistry needs to emphasize on behaviour management training and teaching.

Halboub et al. studied the attitude and knowledge of dentists in Saudi Arabia towards antibiotic prescription; they reported that the level of knowledge was barely intermediate and several deficits were identified ${ }^{(21)}$. In this study, about half of all participants felt competent on their knowledge of drug prescription (45.9\%). The underlying reason for this low rate might be that majority of the students did not encounter emergency cases during their practice, which further emphasizes the importance of exposing the students to an emergency clinic and provide them with the proper education.

In this study, $56.9 \%$ and $55.1 \%$ participants were satisfied with their education on the treatments of traumatized deciduous teeth and young permanent teeth, respectively. This might be due to the lack of sufficient number of patients. The results of a study conducted by Al-Shamiri et al. to evaluate dental students' knowledge on traumatic injuries to the teeth showed that majority of the students had insufficient knowledge concerning dental trauma and its management. This highlights the need to improve the knowledge of dental students in dental trauma and its management using a variety of educational methods such as problem-based learning and enriching the curriculum with topics of dental trauma ${ }^{(22)}$.

In this study, $83.4 \%$ of the participants were satisfied with their knowledge on pulp therapy of deciduous teeth. The underlying reason may be that the students received sufficient training on pulpotomy and pulpectomy of deciduous teeth. However, only $45.9 \%$ of the participants were satisfied with their knowledge on pulp therapy of young permanent teeth. This could be because a majority of the participants were unable to perform pulp therapy of young permanent teeth. Moreover, it is a sensitive technique that requires time, special care and equipment to develop proficiency in.

It has been proven that pulpotomy with SSC has a higher success rate over amalgam ${ }^{(23,24)}$. Thus, it is important that the graduate students are able to perform this procedure. In this study, $89.9 \%$ of the participants chose "strongly agree" and "agree" for their ability in placement of stainless steel crowns in children.

If premature extraction or loss of tooth is unavoidable, the safest option to maintain arch space is by placing a space maintainer ${ }^{(25)}$. Therefore, training on this aspect is a major goal to be achieved by the curriculum of paediatric departments in dental schools. Fortunately, in this study, $89 \%$ of the participants expressed educational satisfaction in the training of the space maintainer application method. Only $3.7 \%$ of participants expressed doubts in their abilities to perform restorations on primary teeth, and $93.6 \%$ of the participants were competent in extraction of deciduous teeth. This is perhaps because a large number of patients need these types of treatment; therefore, the students had more practice on this method.

This research has a few limitations. The number of participants was small and represented only one educational institute, which limits the scope of students' satisfaction that could be gathered. In addition, the data were collected from a specific region; hence, the results of this study cannot be generalized to dental students in other cities and countries. 


\section{CONCLUSION}

The results of this study showed that senior dental students expressed educational satisfaction towards most of the clinical education received in the paediatric courses. However, there was a lack of knowledge regarding drug prescription and pulp therapy in young permanent teeth among these students. Moreover, female participants showed more educational satisfaction than did male in a few procedures.

\section{REFERENCES}

1. Petersen PE. Global policy for improvement of oral health in the 21st century - implications to oral health research of World Health Assembly 2007, World Health Organization. Community Dent Oral Epidemiol. 2009;37:1-8.

2. Zhang S, Liu J, Lo ECM, Chu C-H. Dental caries status of Bulang preschool children in Southwest China. BMC Oral Health. 2014;14:16.

3. Prakasha SS, Vinit GBG, Giri KY, Alam S. Feeding practices and early childhood caries: a cross-sectional study of preschool children in kanpur district, India. ISRN Dent. 2013;2013:275193.

4. Perera PJ, Abeyweera NT, Fernando MP, Warnakulasuriya TD, Ranathunga N. Prevalence of dental caries among a cohort of preschool children living in Gampaha district, Sri Lanka: A descriptive cross sectional study. BMC Oral Health. 2012 13;12:49.

5. Pitts NB, Boyles J, Nugent ZJ, Thomas N, Pine CM. The dental caries experience of 5-year-old children in Great Britain (2005/6). Surveys co-ordinated by the British Association for the study of community dentistry. Community Dent Health. 2007 ;24:59-63.

6. Baggio S, Abarca M, Bodenmann P, Gehri M, Madrid C. Early childhood caries in Switzerland: a marker of social inequalities. BMC Oral Health. 2015 22;15:82.

7. Al-Meedani LA, Al-Dlaigan YH. Prevalence of dental caries and associated social risk factors among preschool children in Riyadh, Saudi Arabia. Pakistan J Med Sci. 2016;32:452-6.

8. Jahangiri L, Mucciolo TW, Choi M, Spielman AI. Assessment of teaching effectiveness in U.S. Dental schools and the value of triangulation. J Dent Educ. 2008;72:707-18.
9. Commission on Dental Accreditation. Commission on Dental Accreditation Accreditation Standards for Advanced Education Programs in General Practice Residency. 2015.

10. Virdi MS. Pediatric Dentistry - A Guide for General Practitioner. 1924;(June):50-68.

11. Farshbaf KA, Shahnazi M, Hajizadeh K, Abaszadeh M. Strengths and Weaknesses of Clinical Education Settings from the Viewpoint of Midwifery Students and Educators of Tabriz University of Medical Sciences. FMEJ. 2013;3:7-14.

12. Mokhtari M, Foroozanfar A, Farazi F. Assessment of Final Year Dental Students' Views of Science Education in Dental Implants .J Mash Dent Sch. 2012; 36:157-64

13. Rafeek RN, Marchan SM, Naidu RS, Carrotte P V. Perceived competency at graduation among dental alumni of the University of the West Indies. J Dent Educ. 2004;68:81-8.

14. Sajadi FS , Torabi M, Poreslami H, Babei M. The Attitude of Dental Graduates toward Clinical Education on Pediatric Dentistry. Sch J App Med Sci. 2016;4:1360-5.

15. Davidovitch N, Soen D. Using students' assessments to improve instructors' quality of teaching. J Furth High Educ. 2006 Nov;30:351-76.

16. Victoroff KZ, Hogan S. Students' perceptions of effective learning experiences in dental school: a qualitative study using a critical incident technique. J Dent Educ. 2006;70:124-32.

17. McWhorter AG. Treatment planning for the pediatric patient. Tex Dent J. $2010 ; 127: 1275-80$.

18. Zero D, Fontana M, Lennon AM. Clinical applications and outcomes of using indicators of risk in caries management. J Dent Educ. 2001;65:1126-32.

19. Togoo RA, Al-Rafee MA, Kandyala R, Luqam M, AlBulowey MA. Dentists' opinion and knowledge about preventive dental care in Saudi Arabia: A nationwide crosssectional study. J Contemp Dent Pract. 2012;13:261-5.

20. Harzer W, Oliver R, Chadwick B, Paganelli C. Undergraduate Orthodontic \&amp; Paediatric Dentistry Education in Europe-The DentEd Project. J Orthod. 2001;28:97-102.

21. Halboub E, Alzaili A, Quadri MFA, Al-Haroni M, AlObaida MI, Al-Hebshi NN. Antibiotic Prescription 
Knowledge of Dentists in Kingdom of Saudi Arabia: An Online, Country-wide Survey. J Contemp Dent Pract. 2016;17:198-204.

22. Al-Shamiri HM, Alaizari NA, Al-Maweri SA, Tarakji B. Knowledge and attitude of dental trauma among dental students in Saudi Arabia. Eur J Dent. 2015;9:518-22.

23. Holan G, Fuks AB, Ketlz N. Success rate of formocresol pulpotomy in primary molars restored with stainless steel crown vs amalga. Pediatr Dent.2002;24:212-6.

24. Sonmez D, Duruturk L. Success rate of calcium hydroxide pulpotomy in primary molars restored with amalgam and stainless steel crowns. BDJ. 2010;208:E18

25. Wright GZ, Kennedy DB. Space control in the primary and mixed dentitions. Dent Clin North Am. 1978;22:579-601. 